\title{
Dimensional modelling of the fuel outgassing phenomenon: Improving flammability assessment of aircraft fuel tanks
}

\author{
A. P. Harris \\ adam.harris1@virgin.net \\ Airbus, EV Flight and Integration Test Centre \\ Bristol, UK \\ N. M. Ratcliffe \\ Centre for Research in Analytical, Materials and Sensor Science \\ University of the West of England \\ Bristol, UK
}

\begin{abstract}
Fuel outgassing (oxygen evolution) within aircraft fuel tanks presents a serious flammability hazard. Time constants representing oxygen transfer rate, from the fuel into a tank's ullage, are used to model the effect of outgassing on tank flammability. These time constants are specific to a single aircraft type and flight envelope and may not accurately represent fuel outgassing behaviour for other aircraft types with differing fuel tank configurations and flight envelopes. To improve current modelling practice for more accurate flammability analysis dimensional modelling has been used to determine the rate of oxygen evolution from Jet A-1 fuel in an aircraft fuel tank. Measurements of oxygen evolution rate, made on a dimensionally similar model, have been projected to an A320 aircraft. The evolution of oxygen from the fuel was found to increase monotonically with time. Fitting the test data with an inverseexponential function enabled oxygen release rate and its associated time constant $(\tau)$ to be determined. Dimensional modelling of aviation fuel outgassing using model fuel tanks will enable oxygen evolution rate from aviation fuel to be determined for a wide range of aircraft fuel tank configurations and environments without the need for flight testing. In turn the accuracy of flammability assessment of aircraft fuel tanks will be improved and significant cost savings made.
\end{abstract}

\section{NOMENCLATURE}

$\begin{array}{ll}b & \text { regression model constant } \\ c & \text { regression model constant } \\ D & \text { impeller diametre }\end{array}$

$i \quad$ time step

$K, k \quad$ rate constant of oxygen evolution

$\mathrm{mO}_{2}$ mass of oxygen released from fuel at time, $t$

$m \dot{O}_{2} \quad$ instantaneous mass release rate of oxygen

$m_{f} \quad$ mass of fuel

$N \quad$ impeller rotational speed

$\mathrm{Np} \quad$ impeller power number

$\mathrm{Nq} \quad$ impeller flow number

$N p_{\text {std }} \quad$ ref. impeller power number

$N q_{\text {std }} \quad$ ref. impeller flow number

$N_{v}$

$N_{d}$ number of dimensionless variables number of fundamental dimensions $\%$ volume fraction of oxygen at time step $\%$ volume fraction of oxygen in ullage total pressure in ullage partial pressure of oxygen in ullage Rate of Change of ullage pressure partial pressure of oxygen dissolved in fuel power in stirred tank pressure at altitude volumetric impeller flow time impeller torque altitude

\section{Greek symbols}

$\alpha \quad$ fuel agitation factor

$\sigma_{f} \quad$ fuel surface tension

$\rho \quad$ liquid density

$\tau \quad$ time constant of oxygen evolution 


\subsection{INTRODUCTION}

Fuel outgassing significantly affects the flammability of an aircraft fuel $\operatorname{tank}^{(1,2)}$. Within the past decade airworthiness authorities have mandated that flammability analyses, for commercial transport aircraft, fitted with nitrogen inerting systems, take into account the release of oxygen from the fuel. The Fuel Tank Flammability Assessment Method $^{(3)}($ FTFAM), engendered by the Federal Aviation Administration (FAA) uses exponential time constants of oxygen release to model fuel outgassing rate and ullage oxygen concentration using Equation (1). The exponential time constant $(\tau)$ represents the time taken for $(1-1 / e)$, or $63 \cdot 2 \%$ of the total mass of oxygen, that will evolve from the fuel, to be transferred into the tank ullage.

$$
\frac{O_{2, i}-O_{2, i-1}}{20 \cdot 9-O_{2, i-1}}=1-e^{\frac{-t}{\tau}}
$$

A key issue for the flammability analyst is that the time constants used in the analysis method are specific to a single aircraft type and set of fuel tank conditions from which they were determined during a single flight test. Consequently, using the method's universal time constants to model fuel outgassing in other aircraft fuel tanks, under differing environmental conditions, may lead to serious errors. To overcome this problem we can turn to laboratory based study of fuel outgassing in model tanks to determine specific fuel outgassing time constants and rates for different aircraft types and conditions. The laboratory based modelling approach can be conducted expediently and cover a wide range of fuel tank environments at a fraction of the cost of aircraft flight testing.

Although previous laboratory studies ${ }^{(4)}$ made good progress towards identifying the key variables that govern fuel outgassing, direct use of this data in fuel tank flammability analyses is not advised. The difficulty arises because previous investigators overlooked the importance of dimensional similarity in their model testing. Dimensional similarity is achieved by ensuring the numerical values for all defining dimensionless variables within two physical systems i.e. model and prototype, are equal. Without establishing dimensional similarity between their physical models and the aircraft fuel tanks, correlating the behaviour of variables, key to fuel outgassing, between the two systems becomes an almost impossible task. Consequently, results and mathematical models of fuel outgassing rate and ullage oxygen concentration from such tests cannot be projected to full-size aircraft. A solution to this problem can be achieved through the use of dimensional modelling. Dimensional modelling ${ }^{(5)}$ is a powerful tool which allows the behaviour of two physical systems (model and prototype) to be closely correlated, where the results of measurements on either one can be projected accurately to the other. At this point an important

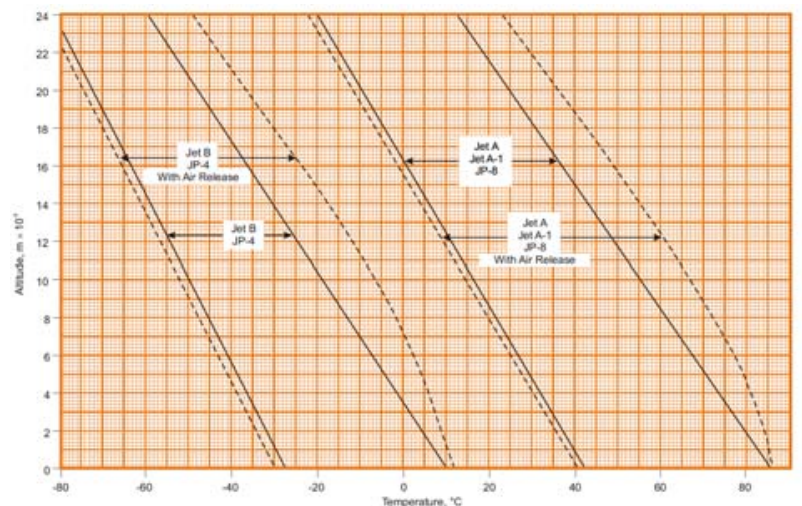

Figure 1. The effect of oxygen-rich air release from aviation turbine fuels on aircraft fuel tank flammability at different altitudes and fuel temperatures. fact must be emphasised; a model can be dimensionally similar to a prototype without being geometrically similar. Geometric similarity is neither a sufficient nor a necessary condition for dimensional similarity.

In this study dimensional modelling was applied to determine the oxygen release rate from Jet A-1 fuel in an Airbus A320 aircraft fuel tank environment. Dimensionless variables were derived using a matrix-based algorithm and the Model Law established, from which, laboratory based model fuel tank tests were conducted and the results projected to the A320 aircraft. The aim of this work is to provide oxygen release rate data that will enhance fuel tank flammability analysis within the aerospace industry.

\subsection{Fuel outgassing}

Reducing atmospheric pressure above the fuel surface in vented tanks during aircraft climb promotes the release of oxygen-rich air from the fuel (fuel outgassing). As a consequence the fuel tank flammability envelope is broadened as both upper and lower flammability limits move further apart as illustrated in Fig. 1. Temperature dependent solubility co-efficients of oxygen in aviation turbine fuels are higher than nitrogen and lead to an oxygen-rich composition in the released air. Figure 2 shows Ostwald solubility co-efficients of air gases in a range of aviation turbine fuels as a function of temperature. Under certain conditions the oxygen content within the evolved air can be as high as $37 \%$ by volume ${ }^{(6)}$. The rate of air release is understood to be governed by several variables; the degree of fuel agitation, Rate of Change of atmospheric pressure, degree of air-supersaturation, level of air solubility, fuel temperature and the ullage/fuel ratio. Air release is initiated when the partial pressures of the air gases within the ullage and the dissolved gas pressures within the fuel reach a critical differential. Schweitzer and Szebehely ${ }^{(4)}$ examined air evolution rate in a number of liquids, including aircraft engine fuels. They found the rate of air evolution to be proportional to the level of air-supersaturation. Supersaturation occurs when the amount of gas dissolved in the liquid is greater than the amount that would correspond to the gas pressure above the liquid. While the work was pioneering in this field only a limited range of environmental conditions were examined and the effects of scale within their experiments were not investigated. These factors prevent use of this data for aircraft flammability analysis. Kosvic et $a l^{(1)}$ developed a theoretical model of air evolution rate to understand

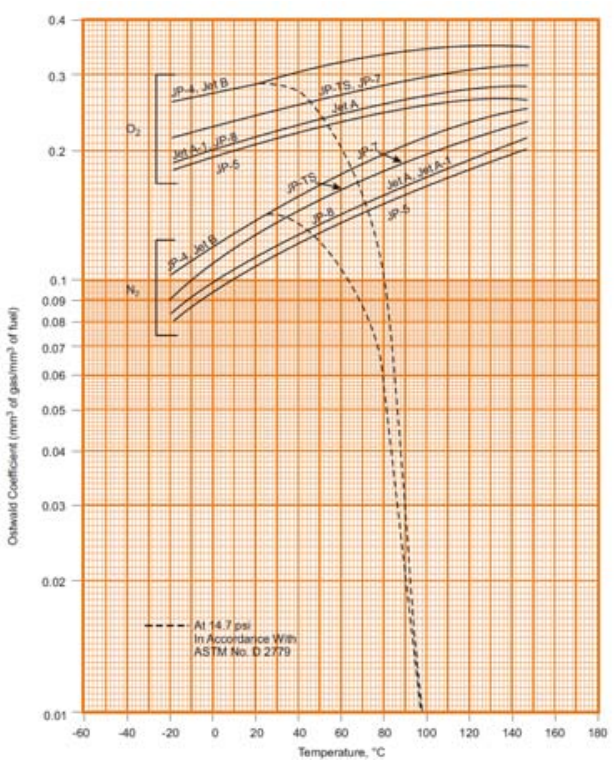

Figure 2. Ostwald solubility co-efficients of oxygen and nitrogen gases in aviation turbine fuels as a function of temperature. 
Table 1

Key variables relevant to the rate of oxygen evolution from aviation turbine fuel

\author{
Variable \\ oxygen release rate \\ partial pressure of oxygen in ullage \\ partial pressure of oxygen dissolved in fuel \\ fuel agitation factor \\ fuel surface tension \\ rate of change of ullage pressure \\ mass of fuel
}

Symbo
$\dot{m} O_{2}$
$p_{u}$
$p_{f}$
$\alpha$
$\sigma_{f}$
$\dot{p}$
$m_{f}$

its effect on the fuel/air mass ratio in aircraft fuel tanks during flight. The rate of air evolution was found to play a significant role in the formation of flammable fuel-air mixtures. Despite good agreement between fuel/air ratio predictions and laboratory measurements, further testing was required to determine the rate of air evolution as functions of fuel tank vibration level, fuel temperature, rate of ullage pressure decrease and fuel type. Their theoretical model featured an experimentally defined coefficient, $K$, which was dependent on fuel tank geometry, vibration level, fuel type and temperatures used in the laboratory tests. This feature of the model demonstrates the importance of achieving dimensional similarity in laboratory tests if results are to be projected to the aircraft.

Quantifying the oxygen release rate over a wide range of aircraft fuel tank environments will provide a number of benefits. Performance modelling of flammability reduction measures such as Fuel Tank Inerting (FTI) will be improved together with more realistic simulation of the fuel tank ullage environment which is essential for assessing flammability. Improved FTI performance prediction would provide pre-flight, On-Board Inert Gas Generation System, (OBIGGS) design maturity, greatly reducing or eliminating potential system re-design costs. Finally, and perhaps above all, through the factors identified above the aerospace industry will benefit from a higher level of flight safety.

\subsection{DIMENSIONAL MODELLING}

The relevant variables that influence the rate of oxygen evolution from aviation turbine fuel were determined by previous workers ${ }^{(4,6)}$ and confirmed through the author's own a priori experimentation. These key variables are shown in Table 1, together with their physical dimensions using the SI (kilogram, metre, second) dimensional system.

By the Szirtes algorithm the variables in Table 1 were used to construct the Dimensional Set. The Dimensional Set consists of 4 matrices. The elements of the $\mathbf{A}$ and $\mathbf{B}$ matrices are simply the exponents of the fundamental dimensions involved in the particular variable. The $\mathbf{C}$ matrix is determined from the Fundamental Formula $^{(5)}$;

$$
\mathbf{C}=-\mathbf{D} \cdot\left(\mathbf{A}^{-1} \cdot \mathbf{B}\right)^{T}
$$

and the D matrix is an Identity Matrix. Accordingly, the Dimensional Set follows as shown in Fig. 3.

Thus we have $N_{v}=7$ variables and $N_{d}=3$ dimensions. Therefore, by Buckingham's theorem ${ }^{(7)}$, the number of dimensionless variables is $N_{v}-N_{d}=4$. They are, by the Dimensional Set presented above;

$$
\pi_{1}=\frac{\dot{m} O_{2}}{\alpha} ; \pi_{2}=\frac{p_{u}}{p_{f}} ; \pi_{3}=\frac{\sigma_{f} \cdot m_{f}}{\alpha^{2}} ; \pi_{4}=\frac{\dot{p} \cdot m_{f}}{\alpha \cdot p_{f}}
$$

Where, as required, all of the above $\pi$ variables have the dimension of 1 .

Dimension
$\mathrm{kg} / \mathrm{s}$
$\mathrm{kg} /\left(\mathrm{m} \cdot \mathrm{s}^{2}\right)$
$\mathrm{kg} /\left(\mathrm{m} \cdot \mathrm{s}^{2}\right)$
$\mathrm{kg} / \mathrm{s}$
$\mathrm{kg} / \mathrm{s}^{2}$
$\left(\mathrm{~kg} / \mathrm{s}^{2} \cdot \mathrm{m}\right) / \mathrm{s}$
$\mathrm{kg}$

Remark

mass release rate

related to oxygen concentration in ullage related to oxygen concentration in fuel displacement of fuel mass per unit time energy barrier gas breaks for outgassing related to aircraft climb rate fuel load in aircraft tank

\subsection{Sequence of physical variables in dimensional set}

The sequence of physical variables appearing in the Dimensional Set presented in Fig. 3 was arranged such that the dependent variable $\mathrm{mO}_{2}$ features in the leftmost position. Variables, $p_{f}$ and $p_{u}$ were split between the $\mathbf{A}$ and $\mathbf{B}$ matrices respectively as no two or more variables, with identical dimensions and hence identical columns may exist within the A matrix as A must be non-singular.

\subsection{Scale Factors and the Model Law}

Having identified the dimensionless variables relevant to our oxygen evolution rate analysis the Scale Factors of our physical variables set out in Table 1 can now be defined. A Scale Factor for a particular variable is the quotient of the magnitudes of the variable for the prototype (aircraft fuel tank) and the model (laboratory fuel tank) e.g. for fuel agitation factor, $\alpha$ can be written as;

$$
S_{\alpha}=\frac{\alpha_{2}}{\alpha_{1}}
$$

where the subscripts 2 and 1 indicate model and prototype respectively. For our seven physical variables identified in Table 1 and the dimensionless variables presented in Equation (3) the Scale Factors follow accordingly;

$S_{\dot{m} O_{2}}=\frac{\dot{m} O_{2(2)}}{\dot{m} O_{2(1)}} ; S_{p u}=\frac{p_{u_{2}}}{p_{u_{1}}} ; S_{p_{f}}=\frac{p_{f_{2}}}{p_{f_{1}}} ; S_{\alpha}=\frac{\alpha_{2}}{\alpha_{1}} ; S_{\sigma_{f}}=\frac{\sigma_{f_{2}}}{\sigma_{f_{1}}} ; S_{m_{f}}=\frac{m_{f_{2}}}{m_{f_{1}}} ; S_{\dot{p}}=\frac{\dot{p}_{2}}{\dot{p}_{1}}$

Having defined the Scale Factors we now define the Model Law. The Model Law is the relation among the above Scale Factors relevant to our oxygen release rate analysis. From the $\pi$ variables obtained from the Dimensional Set, as shown in Equation (3) the Model Law is given as;

$$
S_{\dot{m} O_{2}}=S_{\alpha} ; S_{p_{u}}=S_{p_{f}} ; S_{\sigma_{f}}=\frac{S_{\alpha}^{2}}{S_{m_{f}}} ; S_{m_{f}}=\frac{S_{\alpha}^{2}}{S_{\sigma_{f}}} ; S_{\dot{p}}=\frac{S_{\alpha} \cdot S_{p_{f}}}{S_{m_{f}}}
$$

The Scale Factor for fuel surface tension becomes equal to unity if the aviation fuel (Jet A-1) in the model tank is maintained at the

\begin{tabular}{l|cccc|ccc}
$\mathrm{B}$ matrix & $\dot{m} \mathrm{O}_{2}$ & $p_{u t}$ & $\sigma_{f}$ & $\dot{p}$ & $\alpha$ & $p_{f}$ & $m_{f}$ \\
\hline $\mathbf{m}$ & 0 & -1 & 0 & -1 & 0 & -1 & 0 \\
$\mathbf{k g}$ & 1 & 1 & 1 & 1 & 1 & 1 & 1 \\
$\mathbf{s}$ & -1 & -2 & -2 & -3 & -1 & -2 & 0 \\
\hline$\pi_{1}$ & 1 & 0 & 0 & 0 & -1 & 0 & 0 \\
$\pi_{2}$ & 0 & 1 & 0 & 0 & 0 & -1 & 0 \\
$\pi_{3}$ & 0 & 0 & 1 & 0 & -2 & 0 & 1 \\
$\pi_{4}$ & 0 & 0 & 0 & 1 & -1 & -1 & 1
\end{tabular}

Figure 3. The dimensional set. 

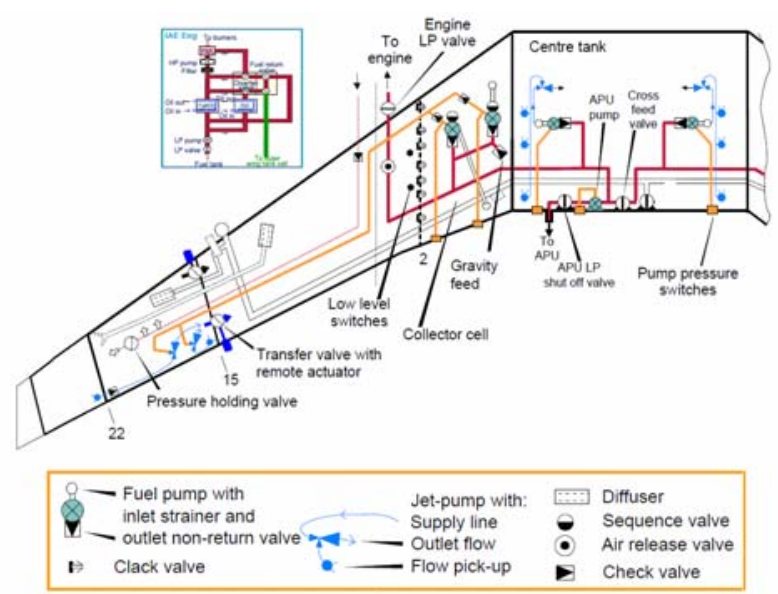

Figure 4. A320-200 engine fuel feed system and tank layout (left hand shown).

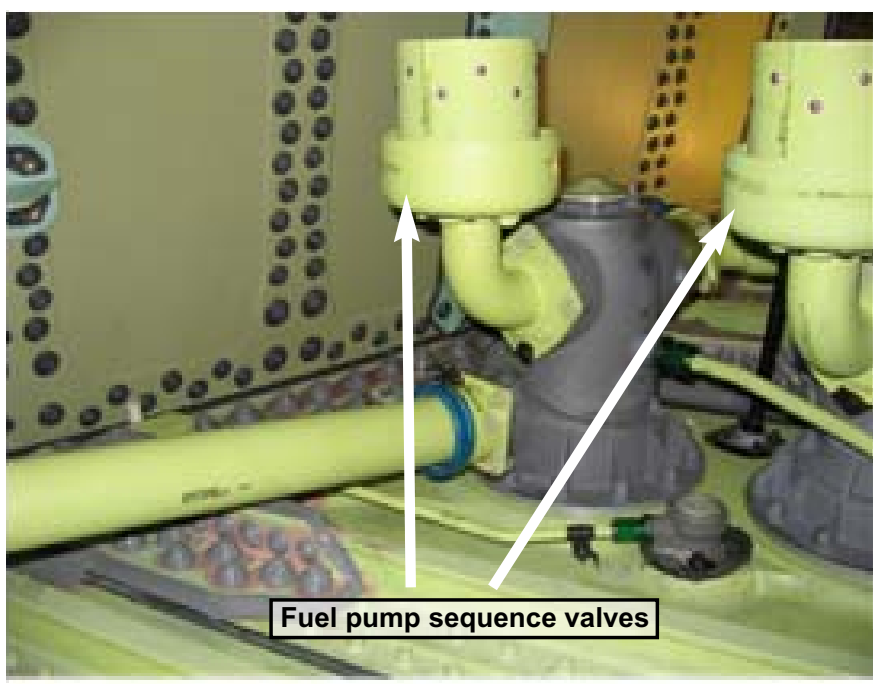

Figure 5. A320 inner wing collector cell.

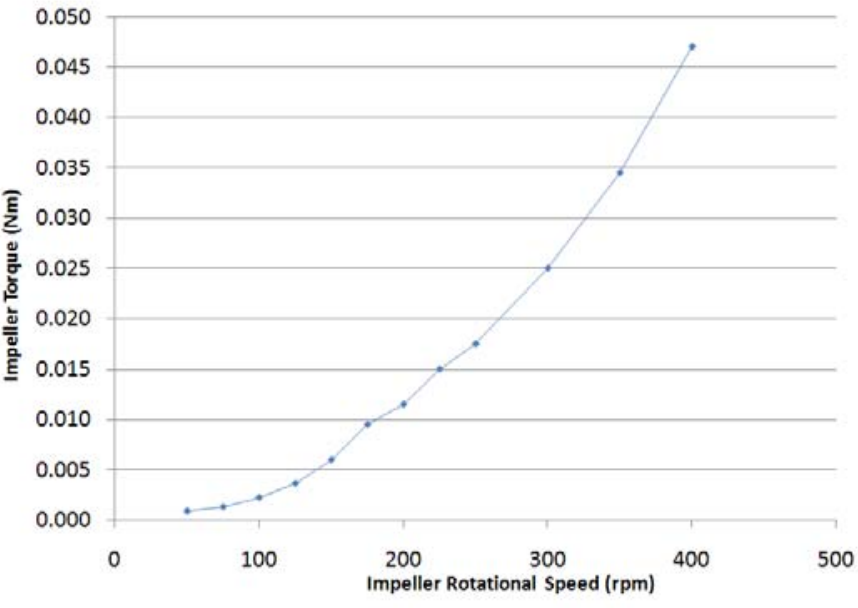

Figure 6. IKA R1373 impeller torque vs rotational speed in water at $17^{\circ} \mathrm{C}$. same temperature as the prototype (aircraft fuel tank). By reducing the model tank's ullage pressure to the same condition experienced by the aircraft during flight, ullage and fuel oxygen partial pressures, in the model tank and prototype will reach similar values due to outgassing as equilibrium is eventually established. Taking advantage of the fact that aviation fuel will obey Henry's Law for both systems the Model Law is further simplified to;

$$
S_{\dot{m} O_{2}}=S_{\alpha} ; S_{p_{u}}=S_{p_{f}} ; S_{m_{f}}=S_{\alpha}^{2} ; S_{\dot{p}}=\frac{S_{\alpha}}{S_{m_{f}}}
$$

\subsection{A320 aircraft inner wing tank analysis}

To determine the mass of fuel, agitation factor and Rate of Change of ullage pressure needed in our model fuel tank a typical fuel system operating condition from the Airbus A320-200 aircraft ${ }^{(8)}$ was used. In the A320 aircraft a total of three 'boost' pumps located within the wing and centre tanks deliver fuel to each engine fuel system. The collector cell pumps feature 'sequence valves' which reduces their fuel delivery pressure to a value below that of the centre tank pump, biasing fuel delivery from the centre tank. When the centre tank fuel quantity falls to a minimum level the pump is switched off and engine fuel supply is maintained by the collector cell pumps. During aircraft operation the mass of fuel held within the collector cells is continuously agitated by fuel re-circulating through the pumps and sequence valves. This level of agitation varies as the engine fuel flow rate changes during flight. Flow from the pumps is also provided to drive water scavenge jet pumps (WSJP's) located in the surge and outer wing tanks. Thus the collector cell fuel agitation factor is simply the mass discharge rate of fuel from the sequence valves, estimated from the engine fuel feed rate, jet pump motive flow, engine oil fuel-cooling flow and fuel pump performance. Figure 4 shows the layout of the A320-200 engine fuel feed system and fuel cooled oil circuit of the aircraft's International Aero Engine (IAE) V2500 engine variant and Fig. 5 a photograph of the fuel pump sequence valves.

Table 2 shows values for a typical engine fuel feed operating condition for the A320-200 aircraft. Under these conditions the aircraft's operating altitude is $11,582 \cdot 4 \mathrm{~m}(38,000 \mathrm{ft})$ and fuel temperature $20^{\circ} \mathrm{C}$. Fuel is fed from both collector cell pumps to one engine with an empty centre tank.

Table 2

Typical A320-200 fuel system parameter values at an aircraft operating altitude of $11,582 \cdot 4 \mathrm{~m}(38,000 \mathrm{ft})$ and $20^{\circ} \mathrm{C}$ fuel temperature

$\begin{array}{cc}\text { Fuel System Parameter } & \text { Value }(\mathbf{k g} / \mathbf{s}) \\ \text { WSJP motive flow } & 0.125 \\ \quad \text { engine feed flow } & 0.333 \\ \text { engine oil fuel cooling flow } & 0.333 \\ \begin{array}{c}\text { single pump performance } \\ \text { characteristic at } 11,582 \cdot 4 \mathrm{~m}\end{array} & \\ \quad \begin{array}{l}(38,000 \mathrm{ft}) \text { and } 20^{\circ} \mathrm{C} \\ \text { fuel temperature }\end{array} & 1.944 \\ \text { collector cell fuel agitation factor } & 3.097\end{array}$

\subsection{Model fuel agitation factor, $\left[\alpha_{2}\right]$}

To achieve controlled and repeatable fuel agitation in the model fuel tank a mixing impeller (IKA R1373) of the radial flow type was selected. Impeller torque was measured in water at $17^{\circ} \mathrm{C}$ over a 50 to 400rpm rotational speed range using a 0 to 0.05 Newton-metre $(\mathrm{Nm})$ Brookfield Rheometer. Dimensionless power and flow numbers ${ }^{(9)}$ for the mixing impeller were calculated from the measured torque 
values. From these numbers the displaced mass of fuel per unit time, in kilograms per second $(\mathrm{kg} / \mathrm{s})$, for the impeller was found. This dimension aligns conveniently with that of the sequence valve fuel discharge rate from which the fuel agitation Scale Factor, $S_{\alpha}$ is calculated and the required fuel agitation factor for the model found. Figure 6 shows a graphical plot of measured impeller torque vs rotational speed.

Power in a stirred $\operatorname{tank}^{(9)}$ is given by;

$$
\mathrm{P}=N p \rho N^{3} D^{5}
$$

Dividing Equation (8) by angular velocity and rearranging yields the dimensionless impeller power number, $N p$;

$$
\begin{gathered}
T=\frac{P}{2 \pi N}=\frac{N p \rho N^{3} D^{5}}{2 \pi N}=\frac{N p \rho N^{2} D^{5}}{2 \pi} \\
N p=\frac{2 \pi T}{\rho N^{2} D^{5}}
\end{gathered}
$$

The dimensionless flow number, $N q$ for a mixing impeller is given by the following relation;

$$
N q=\frac{Q_{i m p}}{N D^{3}}
$$

Since no value of $N q$ for the IKA R1373 impeller was available from the manufacturer it was necessary to estimate it through the onethird power law relation ${ }^{(10)}$;

$$
N q=N q_{s t d} \cdot \sqrt[3]{\left(\frac{N p}{N p_{s t d}}\right)}
$$

The one-third power-law allows estimation of a mixing impeller's flow number based upon known $N p$ and $N q$ values for a similar impeller design. Published values of $N p$ and $N q$ for the RP $4^{(11)}$, a four bladed radial flow mixing impeller of 3.4 and 0.62 respectively were used to calculate $N q$ values for the IKA R1373 impeller. Rearranging Equation (11) provided the fuel volume displaced per unit time by the impeller as a function of rotational speed. Simple conversion using a density value for Jet A-1 fuel at $20^{\circ} \mathrm{C}$ of $800 \mathrm{~kg} / \mathrm{m}^{3}$ provided the fuel agitation factor in units of $\mathrm{kg} / \mathrm{s}$.

Impeller Reynolds number in a stirred tank is considered to be turbulent above a value of 10,000 , at which point, the value of $N p$ is approximately constant.

Our simplified Model Law, given in Equation (7) dictates that the Fuel Mass Scale Factor is proportional to the square of the Fuel Agitation Scale Factor;

$$
S_{m f}=\mathrm{S}_{\alpha}^{2}
$$

Choosing a fuel mass of $100 \cdot 31 \mathrm{~kg}$ in our model tank which corresponds to $75 \%$ full and using a fuel mass of $1038.4 \mathrm{~kg}$ in the A320 aircraft's collector cell at the top-of-climb, gives from the Model Law, the Fuel Agitation Scale Factor;

$$
S_{\alpha}=\sqrt{\frac{100 \cdot 31}{1,038 \cdot 4}}=0 \cdot 310805
$$

From Table 2 the collector cell Fuel Agitation factor is given as $3.097 \mathrm{~kg} / \mathrm{s}$ thus the model agitation factor, $\alpha_{2}$ is;

$$
\begin{gathered}
\alpha_{2}=0.310805 \times 3.097 \\
\alpha_{2}=0.96256 \mathrm{~kg} / \mathrm{s}
\end{gathered}
$$

Linear interpolation of the $\alpha_{2}$ data in Table 3 for a value of $0.963 \mathrm{~kg} / \mathrm{s}$ corresponds to an impeller rotational speed of $325 \mathrm{rpm}$ in the model.

\subsection{Model rate of pressure change, $\left[\dot{p}_{2}\right]$}

In our chosen aircraft case, typical of in-service performance, the A320-200 aircraft climbs linearly from sea-level to $11,582 \cdot 4 \mathrm{~m}$ $(38,000 \mathrm{ft})$ in 18 minutes. The average rate of climb therefore is $643 \cdot 46 \mathrm{~m} / \mathrm{min}(2,111 \cdot 11 \mathrm{ft} / \mathrm{min})$. This rate of climb was used to generate an altitude vs time profile from which a corresponding pressure vs time curve was generated using Equation (16), taken from the $1996 \mathrm{CRC}$ handbook relating pressure to altitude;

$$
P_{(a)}=100 \times\left(\frac{44,331 \cdot 514-z}{11,880 \cdot 516}\right)^{\frac{1}{0.1902632}}
$$

To determine the Rate of Change of pressure with respect to time for the A320 aircraft a regression equation was fitted to the pressure vs time data using Microsoft Excel and differentiated. This resulted in a Rate of Change of pressure for the aircraft of $154 \cdot 58 \mathrm{~Pa} / \mathrm{s}$ at $t=0$. From the Model Law developed in Equation (7) the Rate of Change

\begin{tabular}{|c|c|c|c|c|c|c|c|}
\hline $\begin{array}{l}\text { Speed } \\
(\text { rpm) }\end{array}$ & $\begin{array}{l}\text { Torque } \\
\text { (N.m) }\end{array}$ & Power (W) & $N p$ & $N q$ & $Q_{i m p}\left(\mathrm{~m}^{3} / \mathbf{s}\right)$ & $\begin{array}{c}\text { Fuel } \\
\text { Agitatio } \\
\text { ctor } \alpha_{2}\end{array}$ & Re No. \\
\hline 50 & 0.00090 & 0.0047 & $4 \cdot 85$ & 0.698 & 0.00020 & $0 \cdot 16$ & $4.08 \times 10^{3}$ \\
\hline 75 & $0 \cdot 00130$ & $0 \cdot 0102$ & $3 \cdot 11$ & 0.602 & $0 \cdot 00026$ & $0 \cdot 208$ & $6 \cdot 13 \times 10^{3}$ \\
\hline 100 & 0.00225 & 0.0236 & 3.03 & 0.597 & 0.00034 & $0 \cdot 272$ & $8.17 \times 10^{3}$ \\
\hline 125 & 0.00365 & 0.0478 & $3 \cdot 14$ & 0.604 & $0 \cdot 00043$ & $0 \cdot 344$ & $1.02 \times 10^{4}$ \\
\hline 150 & $0 \cdot 00600$ & 0.0942 & $3 \cdot 59$ & 0.631 & $0 \cdot 00054$ & 0.432 & $1.23 \times 10^{4}$ \\
\hline 175 & $0 \cdot 00950$ & $0 \cdot 1741$ & $4 \cdot 17$ & 0.664 & $0 \cdot 00066$ & 0.528 & $1.43 \times 10^{4}$ \\
\hline 200 & $0 \cdot 01150$ & $0 \cdot 2409$ & $3 \cdot 87$ & 0.647 & $0 \cdot 00074$ & $0 \cdot 592$ & $1.63 \times 10^{4}$ \\
\hline 225 & $0 \cdot 01500$ & 0.3534 & 3.99 & 0.654 & $0 \cdot 00084$ & 0.672 & $1.84 \times 10^{4}$ \\
\hline 250 & $0 \cdot 01750$ & 0.4581 & $3 \cdot 77$ & 0.642 & 0.00092 & 0.736 & $2.04 \times 10^{4}$ \\
\hline 300 & 0.02500 & 0.7854 & $3 \cdot 74$ & 0.640 & $0 \cdot 00110$ & $0 \cdot 88$ & $2.45 \times 10^{4}$ \\
\hline 350 & 0.03450 & $1 \cdot 2645$ & $3 \cdot 79$ & 0.643 & $0 \cdot 00129$ & $1 \cdot 032$ & $2 \cdot 86 \times 10^{4}$ \\
\hline 400 & 0.04693 & 1.9656 & 3.95 & 0.652 & $0 \cdot 00149$ & $1 \cdot 192$ & $3.27 \times 10^{4}$ \\
\hline
\end{tabular}
of Pressure Scale Factor, $S_{p}$, is given by;

where;

$$
S_{\dot{p}}=\frac{S_{\alpha}}{S_{m_{f}}}
$$

$$
S_{\dot{p}}=\frac{0 \cdot 310805}{0 \cdot 0966}=3 \cdot 21744
$$

from which the required model's Rate of Change of pressure at $t=0$

Table 3

IKA R1373 impeller test data using water at $17^{\circ} \mathrm{C}$ 


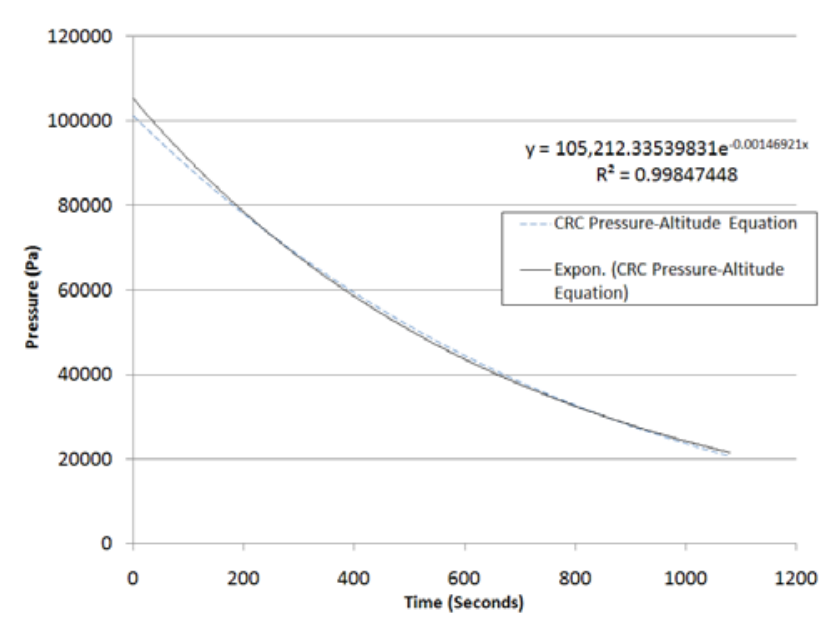

Figure 7. Pressure as a function of time and exponential regression fit for a typical A320-200 aircraft climb from sea-level to $11,582 \cdot 4 \mathrm{~m}$ $(38,000 \mathrm{ft})$ at a rate of $643.46 \mathrm{~m} / \mathrm{min}(2,111 \cdot 11 \mathrm{ft} / \mathrm{min})$ generated from 1996 CRC Handbook equation for pressure-altitude.

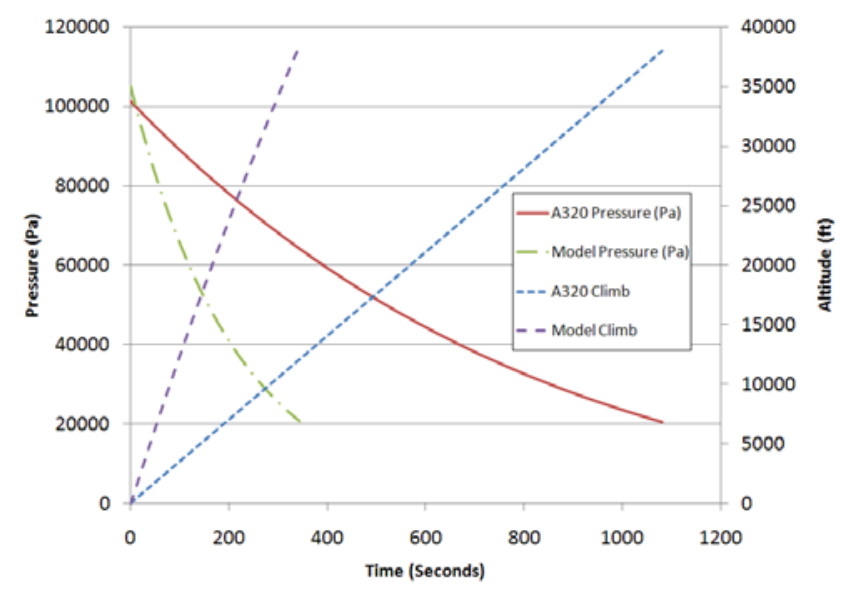

Figure 8. Pressure and altitude plotted as a function of time for the A320 aircraft climb and the model. is given as;

$$
\begin{aligned}
& S_{\dot{P}_{2}}=3 \cdot 21744 \times 154 \cdot 58 \\
& S_{\dot{P}_{2}}=497 \cdot 35187 \mathrm{~Pa} / \mathrm{s}
\end{aligned}
$$

Finally the pressure vs time curve for the model tests were generated by multiplying the rate constant in the Microsoft Excel regression equation by the Rate of Change of Pressure Scale Factor, $S_{p}$. The corresponding rate of climb for the model was found to be $2,070 \cdot 29 \mathrm{~m} / \mathrm{min}(6,792 \cdot 3 \mathrm{ft} / \mathrm{min})$. Figure 7 illustrates the pressure vs time curve generated using the CRC handbook equation and a Microsoft Excel exponential regression equation fit. Figure 8 illustrates the pressure and altitude vs time curves for the A320 aircraft and the model. The slight discrepancy between the intercepts of the aircraft and model pressure curves on the pressure axis at $t=0$ is due to the fit of the Excel regression equation.

\subsection{EXPERIMENTAL METHOD}

A model fuel tank, with $0.75 \times 0.75 \times 0.3 \mathrm{~m}(L \times W \times D)$ internal dimensions, containing $100 \cdot 31 \mathrm{~kg}$ of JET A-1 fuel was installed within a Weiss WK1000 thermal-altitude test chamber. Ullage pressure within the fuel tank was reduced at a rate equivalent to an aircraft climbing at $2,070 \cdot 29 \mathrm{~m} / \mathrm{min}(6,792 \cdot 3 \mathrm{ft} / \mathrm{min})$. Vent valves located within the lid of the tank allowed ullage air to be expelled from the tank or air from the thermal-altitude test chamber to be admitted. The fuel was mechanically stimulated using a mixing impeller (IKA Model No. R1373) at 325rpm. Impeller rotational speed was regulated to within $\pm 1 \mathrm{rpm}$ using a closed loop Proportional-Integral-Derivative (PID) control system. Fuel and ullage temperatures were also conditioned within the test chamber and tank to $20^{\circ} \mathrm{C} \pm 1^{\circ} \mathrm{C}$. Figure 9 illustrates the model fuel tank and experimental set-up.

\subsection{Measurement of oxygen partial pressures}

The \% volume fraction of oxygen within the fuel tank ullage was measured in real-time using an Oxigraf O2G1 analyser. This analyser utilises Tunable Diode Laser Absorption Spectroscopy (TDLAS) to measure oxygen concentration. A gas sample is drawn continuously from the model fuel tank ullage into the analyser's sample cell via an on-board diaphragm pump. The measurement is pressure and temperature compensated by the analyser's hard-coded algorithms to

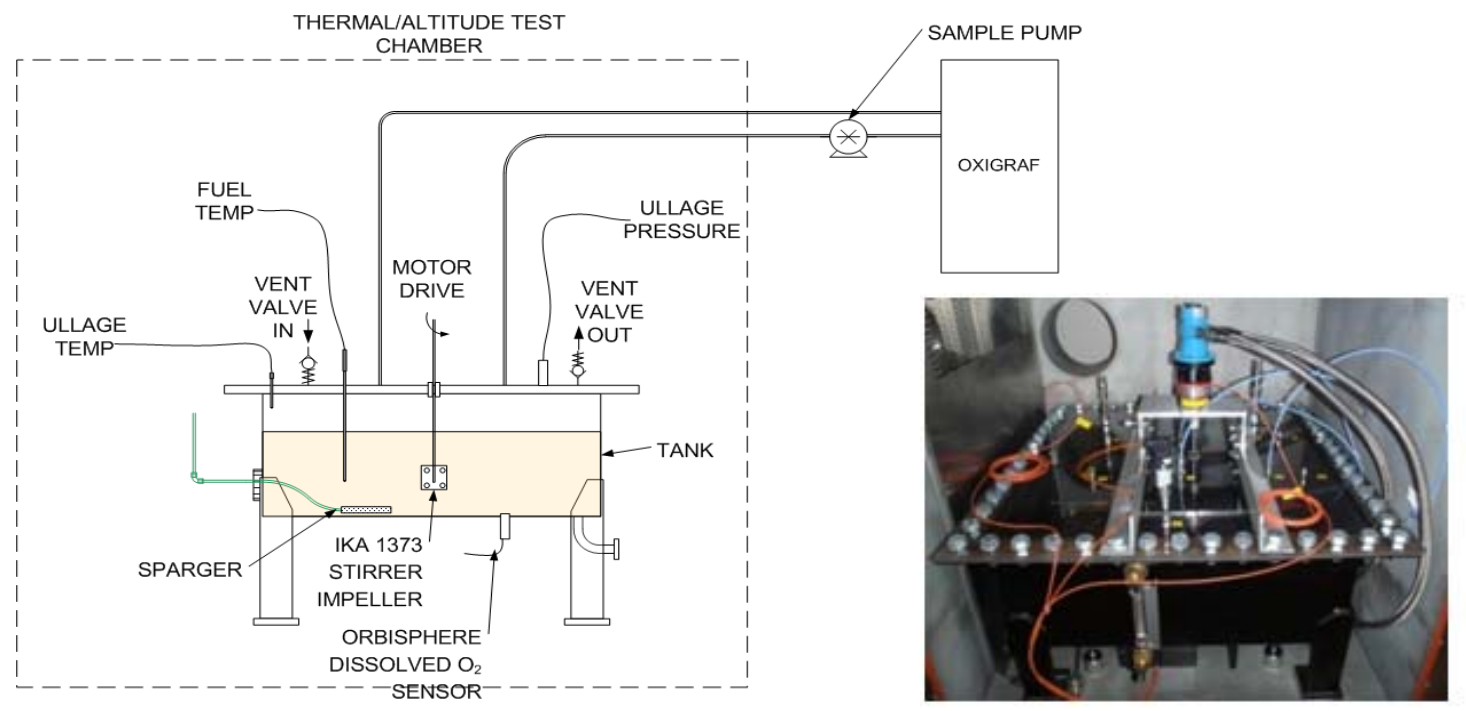

Figure 9. Schematic of model fuel tank and experimental set-up. 
minimise error over the pressure and temperature ranges encountered within the tank's ullage. An uncertainty of measurement analysis was performed prior to testing on the Oxigraf O2G1 analyser using a series of pre-mixed oxygen-in-nitrogen calibration gases spanning a 5 to $35 \%$ oxygen by volume range. Over this oxygen concentration range the analyser was found to have an expanded uncertainty of $\pm 0 \cdot 574 \%$ oxygen by volume. The reported expanded uncertainty is based on a standard uncertainty multiplied by a coverage factor of $k=2$, which provides a confidence level of approximately $95 \%$.

Measurement of dissolved oxygen partial pressure in the fuel was made using an Orbisphere 3660 polarographic oxygen sensor and analyser. This sensor was located inside the base of the fuel tank adjacent to the tip of the mixing impeller. The sensor is constructed from two metal electrodes immersed in an electrolytic solution and separated from the fuel with a Tefzel ${ }^{\circledR}$ gas permeable membrane. An electrical potential is applied between the two electrodes to reduce oxygen that is driven through the membrane by a partial pressure gradient. An electrical current is generated, proportional in magnitude to the partial pressure of dissolved oxygen in the fuel. The uncertainty of measurement of the polarographic oxygen sensor, determined using the same calibration gas method was $\pm 0 \cdot 424 \%$ oxygen by volume.

The partial pressure of oxygen within the ullage was calculated in units of kilopascals $(\mathrm{kPa})$ from the Oxigraf analyser concentration readings and the total pressure in the ullage as follows;

$$
p_{u}=p_{t} \cdot O_{2}
$$

Prior to the beginning of a test the fuel was saturated with dry air (dew point $-75^{\circ} \mathrm{C}$ ) using a gas-liquid contactor, (Mott Corporation), positioned within the tank. Air was introduced at a constant rate of $1.11 \times 10^{-7} \mathrm{~kg} / \mathrm{s}$ until the \% volume fraction of oxygen in the ullage and the partial pressure of dissolved oxygen were in equilibrium. Equilibrium was reached when the readings from the two sensors were approximately equal in magnitude and stable to within $0 \cdot 1 \%$ oxygen by volume in the ullage and $0 \cdot 1 \mathrm{kPa}$ in the fuel. Partial pressures of oxygen in the ullage and fuel, ullage pressure, temperature and mixing impeller rotational speed were logged at a frequency of 1 hertz $(\mathrm{Hz})$ using a National Instruments SCXI 1100 data-logger, Personal Computer (PC) and Labview 7.1 software. Ullage pressure measurement accuracy using a Druck PTX 1,400, 0 to 1,600 millibar absolute (mbar(a)) pressure transmitter was within $0.15 \%$ of full scale while fuel and ullage temperatures were measured using 4-wire Pt100 thermal sensors with an accuracy of $0.01^{\circ} \mathrm{C}$. The test was repeated three times under identical conditions to assess experimental repeatability.

\subsection{RESULTS}

A total of three tests were performed on the model fuel tank. Oxygen concentrations measured in the tank ullage were converted to oxygen partial pressures $(\mathrm{kPa})$ using the total ullage pressure readings. Dissolved oxygen partial pressures in $\mathrm{kPa}$, proportional to the concentration of oxygen in the fuel were used to calculate the rate of oxygen outgassing. Dissolved oxygen partial pressure measurements were first converted to oxygen solubility vs time curves using the method outlined in ASTM D2779 ${ }^{(12)}$. The oxygen solubility data then allowed the total mass of oxygen released from the fuel in $\mathrm{kg}$ to be determined for each test. An exponential function, derived from a first order differential equation, describing oxygen evolution from the fuel was fitted to these data with non-linear least squares using the Single Value Decomposition approach ${ }^{(13)}$.

\subsection{Regression model}

The rate of oxygen gas evolution at a particular time, $t$ is directly proportional to the amount of oxygen gas available to be evolved.

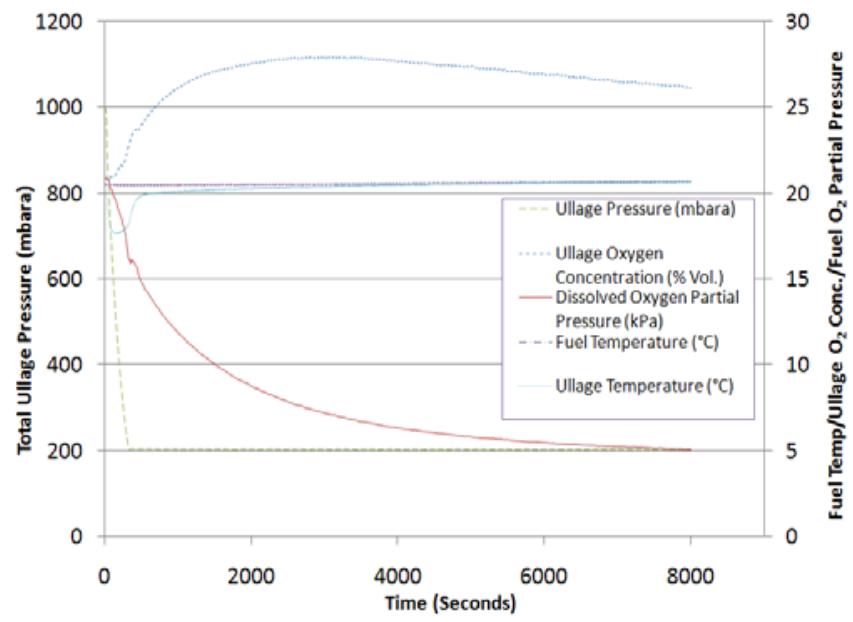

Figure 10. Plot of raw data from test 1.

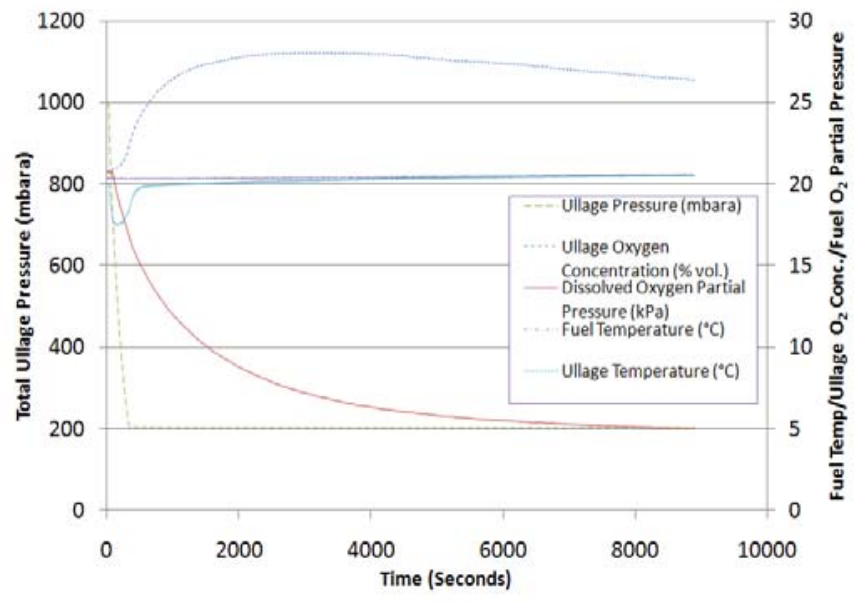

Figure 11. Plot of raw data from test 2.

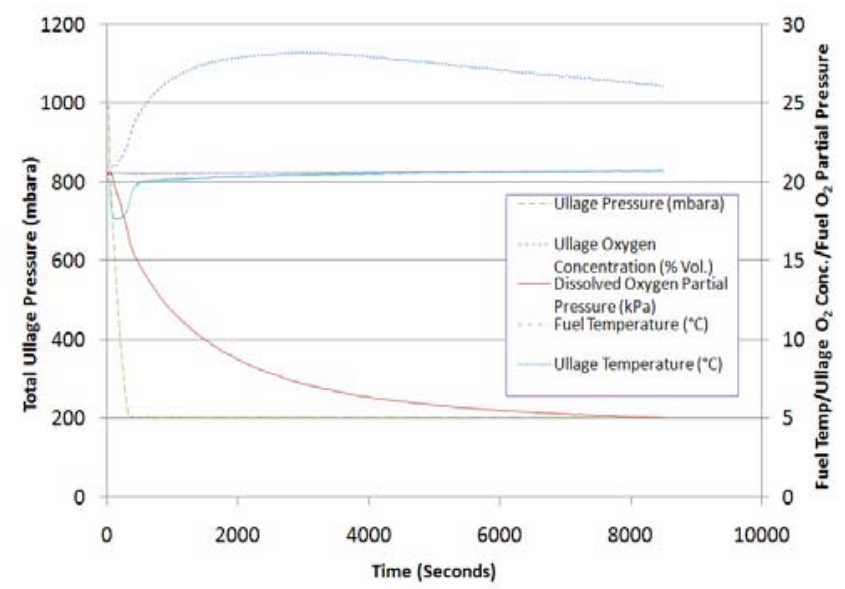

Figure 12. Plot of Raw Data from test 3. 
Denoting the limiting amount (mass) of oxygen evolution by $c$, and if $\mathrm{mO}_{2}$ is the mass of gas evolved at time, $t$ then;

$$
\frac{\mathrm{d}\left(m O_{2}\right)}{\mathrm{d} t}=k \cdot\left(c-m O_{2}\right)
$$

Solving Equation (21) by integration gives;

$$
m \mathrm{O}_{2}=c \cdot\left(1-b \cdot e^{-k t}\right)
$$

where $b$ is an arbitrary constant. Equation (22) represents the mass of oxygen released from the fuel at time, $t$. Differentiating Equation (22) gives an expression for the instantaneous mass release rate of oxygen from the fuel;

$$
\frac{d m O_{2}}{d t}=c \cdot b \cdot k \cdot e^{-k t}
$$

The oxygen mass release rate $(\mathrm{kg} / \mathrm{s})$ was estimated by differentiating the regression equations shown in Table 4 for each set of test data at time $(t=\tau$ where $\tau$ represents the time constant of oxygen mass evolution.

Using the average value of oxygen mass release rate at $(t=\tau)$ from the three model tests in Table 4 and the Model Law developed in Equation (7) the sought after oxygen mass release rate, for the aircraft collector cell, under the chosen conditions can be found from;

$$
S_{\dot{m O}_{2}}=\mathrm{S}_{\alpha}
$$

where from Equation (14);

$$
S_{\text {mO }_{2}}=0 \cdot 310805
$$

from which;

$$
\begin{aligned}
\dot{m} O_{2(1)} & =\frac{1 \cdot 58402 \times 10^{-6}}{0.310805} \\
\dot{m} O_{2} & =5.0965 \times 10^{-6} \mathrm{~kg} / \mathrm{s}
\end{aligned}
$$

In all three tests the ullage oxygen concentration decreased after it had reached equilibrium. Figure 10 shows this occurring at approximately 4,000 seconds into the test. Another interesting feature of the raw data plot shown in Fig. 10 is the drop in ullage temperature as pressure is reduced. Whilst it exerts no influence on the fuel temperature throughout a test, this effect, due to adiabatic cooling, is recovered by the altitude chamber's thermal control system after a short time. Figures 11 and 12 show the raw data plots from two subsequent tests performed under identical conditions. Figure 13 shows the mass of oxygen released over time following conversion of the raw data using the ASTM D2779 calculation method for all three tests. Figure 14 and Table 4 both show that there was very little variation within oxygen mass release rates over the three tests suggesting a good level of experimental repeatability. Root Mean Squared Deviation (RMSD) values for the regression models were very low, ranging from $2 \cdot 1021$ $\times 10^{-4}$ to $2 \cdot 7718 \times 10^{-4}$, indicating a good fit of the regression model to the test data. It is evident from Fig. 14 however that there is slightly greater variation in actual mass release rate between the three tests in the initial phase of gas evolution.

The dimensional modelling data table shown in Table 5 features the average value of oxygen mass release rate at $(t=\tau$ from the three model tests and the projected value of oxygen mass release rate for the chosen A320 aircraft case. The table demonstrates identical values (within rounding) of all four dimensionless variables demonstrating the models similarity to the aircraft.

Table 4

Oxygen mass release rates at $(t=\tau)$ from Jet A-1fuel measured in the laboratory model fuel tank

$\begin{array}{ccccc}\text { Test No. } & \frac{d\left(\mathrm{mO}_{2}\right)}{d t}(\mathbf{k g} / \mathbf{s}) & \text { Regression Equation } & \tau(\mathbf{s e c}) & \begin{array}{c}\text { Root Mean } \\ \text { Squared } \\ \text { Deviation (RMSD) }\end{array} \\ 1 & 1.61318 \times 10^{-6} & \mathrm{mO}_{2}=0 \cdot 00625 \cdot\left(1-1 \cdot 01 \cdot e^{-0.00069-t}\right) & 1,441 & 2 \cdot 7556 \times 10^{-4} \\ 2 & 1.55562 \times 10^{-6} & m \mathrm{O}_{2}=0 \cdot 00623 \cdot\left(1-0 \cdot 992 \cdot e^{-0.00068-t}\right) & 1,462 & 2 \cdot 1021 \times 10^{-4} \\ 3 & 1.58326 \times 10^{-6} & m \mathrm{O}_{2}=0 \cdot 00622 \cdot\left(1-1 \cdot 003 \cdot e^{-0.00068-t}\right) & 1,450 & 2 \cdot 7718 \times 10^{-4}\end{array}$

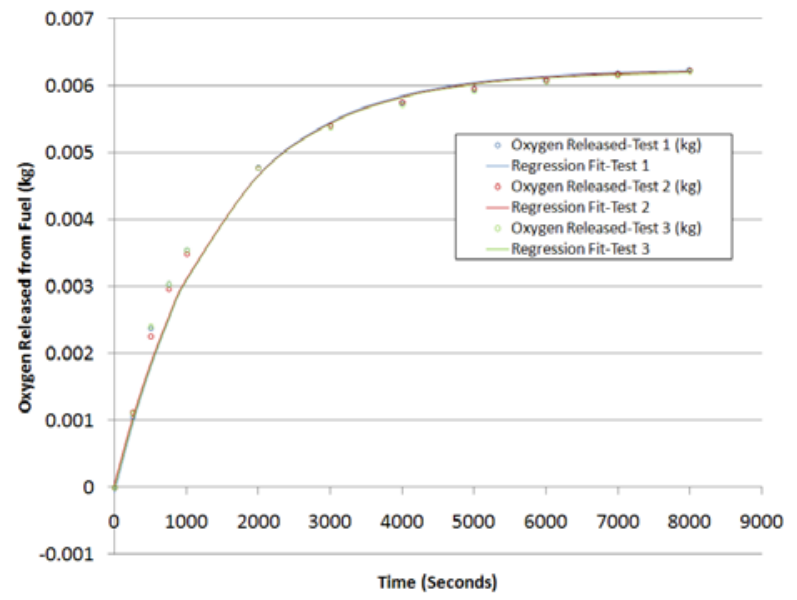

Figure 13. Mass of oxygen released from fuel as a function of time for tests 1 to 3 .

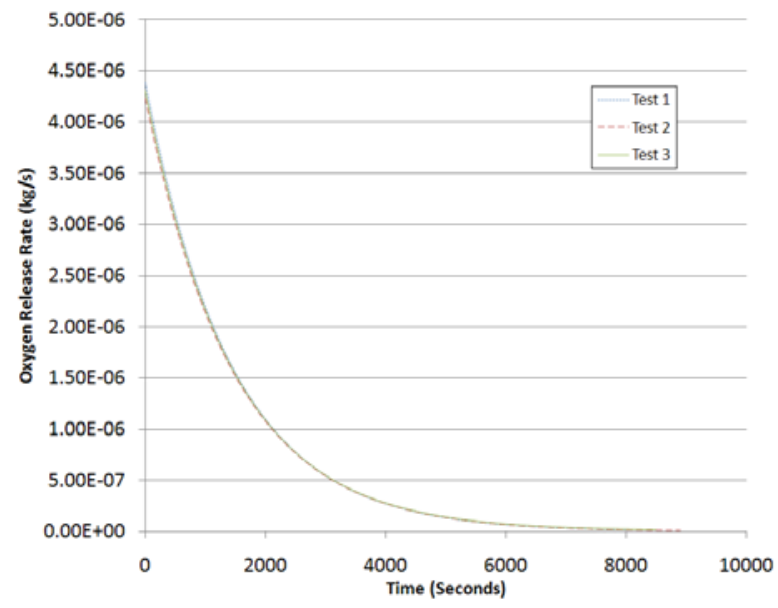

Figure 14. Mass release rate of oxygen as a function of time for tests 1 to 3 . 
Table 5

Dimensional modelling data table for oxygen evolution from aviation fuel

\begin{tabular}{|c|c|c|c|c|c|c|c|}
\hline namo & Variable & dim & & & Scale factor $\mathbf{S}$ & & Category \\
\hline name & symbol & dimension & prototype & model & model/prototype & prototype & model \\
\hline release rate of oxygen & $\dot{m} O_{2}$ & $\mathrm{~kg} / \mathrm{s}$ & $5.0965 \times 10^{-6}$ & $1.58402 \times 10^{-6}$ & $0 \cdot 310805$ & 2 & 3 \\
\hline $\begin{array}{l}\text { partial pressure of } \\
\text { oxygen in ullage }\end{array}$ & $\mathrm{pu}$ & $\mathrm{kg} / \mathrm{s}^{2} \cdot \mathrm{m}=(\mathrm{Pa})$ & $5,718 \cdot 46$ & $5,718 \cdot 46$ & 1 & 1 & 3 \\
\hline fuel surface tension & $\sigma_{f}$ & {$\left[\mathrm{~kg} / \mathrm{s}^{2}\right]=\mathrm{N} / \mathrm{m}$} & $0 \cdot 0281$ & $0 \cdot 0281$ & 1 & 1 & 1 \\
\hline $\begin{array}{l}\text { rate of change of } \\
\text { ullage pressure }\end{array}$ & $\dot{p}$ & $\begin{array}{l}\left(\mathrm{kg} / \mathrm{s}^{2} \cdot \mathrm{m}\right) / \mathrm{s}= \\
(\mathrm{Pa} / \mathrm{s})\end{array}$ & $154 \cdot 58$ & $497 \cdot 35187$ & $3 \cdot 21744$ & 1 & 2 \\
\hline fuel agitation factor & $\alpha$ & $\mathrm{kg} / \mathrm{s}$ & $3 \cdot 097$ & $0 \cdot 96256$ & $0 \cdot 310805$ & 1 & 2 \\
\hline $\begin{array}{l}\text { partial pressure of } \\
\text { oxygen dissolved in fuel }\end{array}$ & $p_{f}$ & $\mathrm{~kg} / \mathrm{s}^{2} \cdot \mathrm{m}=(\mathrm{Pa})$ & $5,060 \cdot 11$ & $5,060 \cdot 11$ & 1 & 1 & 3 \\
\hline mass of fuel & $m_{f}$ & $\mathrm{~kg}$ & $1,038 \cdot 4$ & $100 \cdot 31$ & 0.0966 & 1 & 2 \\
\hline dimensionless & $\pi_{1}$ & 1 & $1.64562 \times 10^{-6}$ & $1.64563 \times 10^{-6}$ & - & - & - \\
\hline dimensionless & $\pi_{2}$ & 1 & $1 \cdot 13$ & $1 \cdot 13$ & - & - & - \\
\hline dimensionless & $\pi_{3}$ & 1 & $3 \cdot 0422$ & $3 \cdot 0422$ & - & - & - \\
\hline dimensionless & $\pi_{4}$ & 1 & $10 \cdot 2427$ & $10 \cdot 2428$ & - & - & - \\
\hline categories of variables & 1 & \multicolumn{6}{|c|}{ freely chosen, a priori given, or determined independently } \\
\hline & 2 & \multicolumn{6}{|c|}{ determined by application of the model law } \\
\hline & 3 & \multicolumn{6}{|c|}{ determined by measurement on the model } \\
\hline
\end{tabular}

\subsection{DISCUSSION}

Dimensional modelling has been used to estimate the mass release rate of oxygen within an A320 aircraft fuel tank from measurements made on a laboratory model. The oxygen release rate measurements made on the model are bounded by the measurement uncertainty established for the polarographic oxygen sensor set-out in section 3.1. By using the Model Law established for oxygen release rate it is clear to see the values measured on the physical model differ appreciably from those projected to the aircraft. This result re-iterates the importance of ensuring dimensional similarity between the physical model and the aircraft case if oxygen evolution data, gathered from laboratory testing is to be used in aircraft flammability analyses. Incorrect values for the rate of oxygen mass release from the fuel will lead to errors in ullage oxygen concentration estimation in the flammability analysis. The impact of this may be far-reaching, where in the worst case the percentage of flight time the fuel tank was flammable is underestimated within the analysis. Studies conducted in the $1950 \mathrm{~s}$ by the Royal Aircraft Establishment ${ }^{(14)}$ (RAE) into oxygen evolution rate from aviation kerosene, in which dimensional similarity was not considered provide contrasting results and help to highlight this very important point. The RAE tests were conducted using approximately 1 litre of fuel at $23^{\circ} \mathrm{C}$, contained in an unstirred cylindrical glass vessel. The ullage pressure in the vessel was reduced at a rate equivalent to an aircraft climbing at $914.4 \mathrm{~m} / \mathrm{min}$ $(3,000 \mathrm{ft} / \mathrm{min})$ from 0 to $11,430 \mathrm{~m}$ ( 0 to $37,500 \mathrm{ft})$. Under these conditions the RAE measured an oxygen release rate from the fuel, at $11,430 \mathrm{~m}(37,500 \mathrm{ft})$, of $1.009 \times 10^{-7} \mathrm{~kg} / \mathrm{s}$. This value is $1,470 \%$ less than the average oxygen mass release rate measured on our dimensionally similar model as shown in Table 5. Although the RAE release rate values are expected to be much lower than those measured in this study because the fuel was quiescent and the climb rate used was less than half, one can appreciate the consequences of severely underestimating the oxygen release rate in the aircraft if such a value were to be used from a dimensionally dissimilar laboratory model.

The application of dimensional modelling to the problem of fuel outgassing has shown that dimensional similarity can be achieved between model and prototype with a geometrically dissimilar model.
This is highly convenient and allows the experimenter a free hand to shape the model without the need to reproduce the complex geometry of an aircraft fuel tank.

A demonstration of how aviation turbine fuel obeys Henry's Law is shown in Fig. 15. The effect of reducing ullage pressure in the stirred model fuel tank promotes dissolved gas evolution and results in the final equilibration of ullage and fuel oxygen partial pressures. This data clearly supports the assumption made in Section 2.3 leading to the simplification of the Model Law given in Equation (7).

The observed decrease in ullage oxygen concentration beyond equilibrium, (approximately 4,000 seconds into test) is most probably due to an increasing build-up of fuel vapour within the tank's ullage. The partial pressure of oxygen in the fuel, at and beyond this point is not decaying significantly, indicating that the majority of dissolved oxygen has already evolved from the fuel into the ullage. With continuous fuel vapour generation due to low pressure conditions and mixing impeller agitation, hydrocarbon

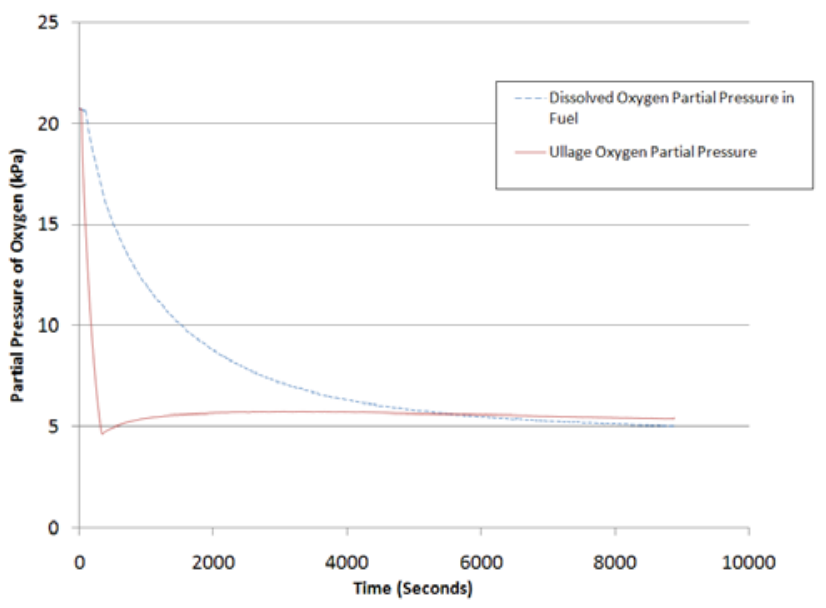

Figure 15. Oxygen partial pressures as a function of time due to outgassing of dissolved air from aviation turbine fuel under reduced ullage pressure and agitated fuel conditions during test 2 . 
vapours will displace oxygen and nitrogen gases in the ullage reducing their concentrations. This hypothesis is supported by the findings of the US Air Force ${ }^{(15)}$ in their studies on oxygen evolution from fuels with varying vapour pressures and fuel temperatures in model test tanks.

Having now established the Model Law for oxygen mass release rate it is possible to conduct further tests on our laboratory model or other models to estimate oxygen mass release rate for various fuel tank conditions and aircraft types. This would not only enable assessment to be made of how each physical variable influences the rate of oxygen release but provide a clear picture under which fuel tank conditions and on which type(s) of aircraft, oxygen release rate, has the largest effect on fuel tank flammability. Dimensional modelling of the fuel outgassing phenomenon could be used to establish if the generic time constants featured within the FTFAM were appropriate for a given aircraft fuel tank and operating condition.

\subsection{CONCLUSIONS}

1. Dimensional modelling has been used to calculate the rate of oxygen outgassing from aviation fuel within an A320 aircraft fuel tank.

2. Oxygen outgassing rate from aviation fuel has been measured within a model fuel tank which was shown to be dimensionally similar to an aircraft fuel tank.

3. Dimensional modelling of the fuel outgassing phenomenon has shown that dimensional similarity between model and prototype can be achieved using a geometrically dissimilar model.

4. Dimensional modelling can be used as a cost effective alternative to flight testing for calculating the release rate of oxygen from aviation fuel to support fuel tank flammability analyses.

5. Further dimensional modelling studies of the fuel outgassing phenomenon are required to understand the suitability of existing fuel outgassing models and time constants within the FTFAM.

\section{ACKNOWLEDGEMENTS}

The authors would like to thank Airbus for funding the work programme and acknowledge contributions from Dr S. Smith at the University of the West of England, Mr S. Sharma of Airbus, Mr D.J. Oram and Dr T. Szirtes.

\section{REFERENCES}

1. Kosvic, T., Zung, L.B. and Gerstein, M. Analysis of Aircraft Fuel Tank Fire and Explosion Hazards, AFAPL-TR-71-7, 1971.

2. Coordinating Research Council. Handbook of Aviation Fuel Properties, CRC Report No. 635,2004.

3. Summer, S.M. Fuel Tank Flammability Assessment Method User's Manual, DOT/FAA/AR-05/8 Final Report, 2008.

4. Schweitzer, P.H. and Szebehely, V.B. Gas evolution in liquids and cavitation, J Appl Phys, December 1950, 21, pp 1218-1224.

5. Szirtes, T. Applied Dimensional Analysis and Modeling (2nd ed), Elsevier, Toronto, Canada, 2006.

6. Ross, K. Air Release from Supersaturated Aircraft Fuel, K.195, 1972.

7. Buckingham, E. On Physically Similar Systems, Physical Reviews 1914,4 , p 345 .

8. WARD, I.P. Software Report on 321SYS4, A321/B8101/336/SDF/B81-01/GEN/61/1941,1993.

9. Paul, E.L., Atiemo-Obeng, V.A. and Kresta, S.M. Handbook of Industrial Mixing, Science and Practice, Wiley-Interscience, 2004.

10. Post, T. Personal Communication, Post Mixing Optimization and Solutions, 2010.

11. Weetman, R.J. and Oldshue, J.Y. Comparison of Mass Transfer Characteristics of Radial and Axial Flow Impellers, 6th European Conference on Mixing, Pavia, Italy, ISBN 0947711 33 3, 24-26 May 1988

12. ASTM, Standard Test Method for Estimation of Solubility of Gases in Petroleum Liquids, D2779-92,2002.

13. Haynes, J. Personal communication, Cadre Analytic, 2010.

14. BEDWELL, M.E. Rate of release of dissolved air, oxygen and nitrogen from kerosine during flight, Technical Memo No Chem, 82, 1952.

15. Rотн, A.J. Development and Evaluation of Airplane Fuel Tank Ullage Composition Model, Volume II - Experimental Determination of Airplane Fuel Tank Ullage Compositions, AFWAL-TR-87-2060, 1987. 